\title{
Uma professora no Departamento de Física
}

Lucimeiry Batista da Silva

Glória de Lourdes Freire Rabay

\section{Resumo}

As pesquisas na área da educação superior e de gênero sobre carreiras das ciências exatas, ainda são recentes no Brasil. Para as mulheres, apesar de terem conquistado lugar em profissões ditas "masculinas", esses espaços não são amigáveis. Elas entraram em massa nas universidades, mas não necessariamente como professoras, até mesmo no serviço público, onde já não existem barreiras ao ingresso das mulheres, sua ascensão nos ambientes "masculinos" ainda encontra muitos obstáculos. Este artigo apresenta reflexões sobre a carreira de uma professora do departamento de Física de uma universidade federal, a partir de sua narrativa biográfica. A investigação partiu da seguinte questão norteadora: as relações de gênero afetam a carreira de uma docente do curso de Física? O principal objetivo foi identificar a percepção da discriminação de sexo e gênero na relação entre colegas de trabalho no departamento de Física de uma Instituição Federal de Ensino Superior (IFES) do nordeste brasileiro, sob o ponto de vista de uma das docentes. O embasamento teórico foi pautado nas discussões sobre as relações de gênero e a divisão sexual do trabalho, considerando a cultura e o campo acadêmico. A técnica de coleta de dados empregada foi a de entrevista narrativa biográfica, e foi realizado um ciclo de três entrevistas. Os dados foram analisados, a partir da construção da (auto) biografia, utilizando a análise do discurso. Nos resultados, foi possível identificar que as relações de gênero interferiram na trajetória profissional da docente biografada e as diferenças entre homens e mulheres se apresentam e se reproduzem em todos os tipos de atividades

Palavras chave:Carreira acadêmica feminina. Gênero no campo acadêmico. Mulheres em carreiras masculinas. 


\section{A professor an Physics Department}

Lucimeiry Batista da Silva

Glória de Lourdes Freire Rabay

\section{Abstract}

Higher education and gender research on exact science careers is still recent in Brazil. Women, although they have gained a place in so-called "male" professions, these spaces are not friendly. They have entered the universities en masse, but not necessarily as teachers, even in the public service, where there are no barriers to women's entry, their rise in "male" environments still faces many obstacles. This article presents reflections on the career of a professor of the physics department of a federal university, from her biographical narrative. The research started from the following guiding question: do gender relations affect the career of a physics teacher? The main objective was to identify the perception of gender and gender discrimination in the relationship between co-workers in the physics department of an IFES in northeastern Brazil, from the point of view of one of the teachers. The theoretical basis was based on discussions about gender relations and the sexual division of labor, considering the culture and the academic field. The data collection technique used was the biographical narrative interview, and a cycle of three interviews was performed. Data were analyzed from the construction of (auto) biography using discourse analysis. In the results it was possible to identify that the gender relations interfered in the professional career of the biographed teacher and the differences between men and women present and reproduce themselves in all kinds of activities.

Keywords: Female academic career. Gender in the academic field. Women in male careers. 


\section{Introdução}

A experiência evidencia "a existência de assimetrias de sexo/gênero, nos cursos e carreiras, na formação, na docência e no desenvolvimento profissional docente" (CARVALHO; RABAY; SILVA, 2012, p. 1467), as pesquisas na área de educação superior e de gênero e, especificamente, sobre carreiras das ciências exatas, são recentes no Brasil. As mulheres, apesar de terem conquistado lugar em profissões ditas "masculinas", ainda hoje, em pleno século XXI, esses espaços não são amigáveis para elas.

Na primeira década do século XXI, em geral, há uma equiparação entre mulheres e homens em relação à presença nos bancos escolares em todos os graus educacionais. As diferenças existentes dizem respeito a regiões e países, a áreas do conhecimento e a níveis de qualidade das instituições. Dados apresentados por Carvalho e Rabay (2014, p. 11) informam que no mundo todo as mulheres "são minoria em cursos superiores classificados como nível 6 pela UNESCO - aqueles que oferecem estudos avançados e pesquisa original, articulados a mestrados e doutorados".

Até mesmo em países industrializados, onde as mulheres representam a maioria dos estudantes de nível superior; elas ainda estão restritas a algumas áreas da formação profissional, como: Ciências Sociais e Humanidades, ao contrário das Ciências Naturais, Matemática, Engenharia e Agricultura, onde o predomínio ainda é masculino. E essa restrição, e divisão de áreas, se reflete na segmentação por gênero do mercado de trabalho, que, como observa Castells (2010) "se aproveita de condições sociais específicas da mulher para aumentar a produtividade, o controle gerencial e, consequentemente, os lucros” (p. 197).

Na educação, na década de 1970, as mulheres ingressaram em massa nas universidades, mas não necessariamente nos cursos considerados masculinos, como alunas e, menos ainda, como professoras. Para atuar como professora, essas poucas alunas das áreas masculinas tinham que ser brilhantes, antes da obrigatoriedade dos concursos públicos, a contratação se dava por indicação e convite dos professores. A partir das seleções por concurso para o serviço, público deixaram de existir as barreiras formais ao ingresso das mulheres em carreiras e cargos. E também as mulheres passaram a integrar o corpo docente das universidades públicas na área das ciências exatas, embora ainda hoje este número seja muito inferior ao número de docentes homens.

Este artigo é um recorte de um projeto "guarda-chuva" 33 e, neste estudo busca responder a seguinte questão: as relações de gênero afetam a carreira de uma docente do curso de Física? O principal objetivo foi identificar a percepção da discriminação de sexo e gênero na

33 Projeto: "Relações de gênero em cursos masculinos: Engenharias Mecânica e Civil, Física, Matemática e Ciência da Computação" (apresentado à chamada MCTI/CNPQ/MEC/CAPES em 2010 e renovado em 2014, na chamada 22/2014 para Ciências Humanas e Sociais), coordenado pela professora Maria Eulina Pessoa de Carvalho (CARVALHO, 2014). 
relação entre colegas de trabalho no departamento de Física de uma Instituição Federal de Ensino Superior (IFES) do nordeste brasileiro, sob o ponto de vista de uma das docentes.

Este artigo apresenta reflexões sobre a carreira de uma professora do departamento de Física a partir da narrativa de sua biografia docente.

\section{Gênero e divisão sexual do trabalho}

Bourdieu (2011) considera que a organização simbólica da divisão social do trabalho é "uma construção arbitrária do biológico, e particularmente do corpo, masculino e feminino, [...] que dá um fundamento aparentemente natural à visão androcêntrica da divisão de trabalho sexual e da divisão sexual do trabalho" (p. 33).

Na sociedade moderna, essa divisão passou a ser denominada: "divisão sexual do trabalho", segundo Danièle Kergoat, no Dicionário Crítico do Feminismo (2009). Essa expressão foi inicialmente discutida pelos etnólogos "para designar uma repartição 'complementar' das tarefas entre homens e mulheres nas sociedades que estudavam" (KERGOAT, 2009 p. 67). As antropólogas feministas discordaram dos etnólogos, demonstrando que não é apenas uma complementariedade de tarefas, o que existe é uma relação de poder entre homens e mulheres, em que os homens dominam (KERGOAT, 2009).

Esta divisão está presente em todos os tipos de trabalhos. No campo acadêmico, local desta investigação, não é diferente: a responsabilidade das mulheres acadêmicas é desdobrada entre o público e o privado, assim como sua carga de trabalho, o que pode impactar no seu desenvolvimento e ascensão profissional.

Além disso, no ambiente produtivo existem os espaços culturalmente atribuídos aos homens, que excluem as mulheres, que, inseridas na mesma cultura, muitas vezes contribuem para essa exclusão, principalmente em processos que estão relacionados com uma técnica naturalizada como masculina. Como observam Chabaud-Rycheter e Gardey (2009, p. 244), "a cultura técnica é assim um dos elementos constitutivos da identidade masculina. Excluídas pelos homens das profissões ou dos lugares em que estes fazem técnica, as mulheres o são também porque ali se produz o masculino”.

Essa exclusão sugere que há falta de habilidade técnica das mulheres ("isso não é trabalho de mulher") criando o estereótipo de gênero. O afastamento ou exclusão das mulheres cria uma divisão que é denominada de horizontal, territorial ou espacial. Assim como no ambiente industrial ou fabril, o mesmo ocorre no ambiente acadêmico. As discriminações ocultam desigualdades, que muitas vezes passam despercebidas, mas que criam um ambiente tal, que muitas mulheres desanimam a ponto de algumas abandonarem o campo científico. "As micro-desigualdades criam um ambiente de trabalho e educacional que prejudica o desempenho das mulheres” (PÉREZ SEDEÑO, 2001, p. 16). 
Supostamente, no serviço universitário público não deveria haver a reprodução da discriminação de gênero, em função do caráter público de ingresso e ascensão na carreira docente. Porém, entende-se que a discriminação de gênero é uma prática generalizada na sociedade e poucos compreendem a existência e persistência dessa discriminação, principalmente em se tratando da ascensão na carreira, onde existe o chamado "teto de vidro", ou seja, um limite, invisível, que dá a visão do topo para as mulheres, mas que dificilmente elas ultrapassam. Segundo Steil (1997), este conceito "foi introduzido na década de 1980 nos Estados Unidos para descrever uma barreira que, de tão sutil, é transparente, mas suficientemente forte para impossibilitar a ascensão de mulheres a níveis mais altos da hierarquia organizacional" (p. 62).

As relações de poder e as desigualdades existentes nas convenções de gênero e na heteronormatividade compulsória estão disseminadas na cultura acadêmica e universitária e, também neste espaço, nem sempre são perceptíveis.

A crença da não existência de discriminação na academia pode advir, inclusive, do discurso da neutralidade científica. E esse pressuposto mantém também a ideia da meritocracia: ou as pessoas se esforçam para atingir os mesmos patamares ou, se não alcançam, é porque não tiveram mérito suficiente. Valores relacionados a essas convenções estão presentes na cultura organizacional e acadêmica. Como observa Cabral (2006) áreas como as Engenharias e Computação são campos onde pouco se observa a inserção e atuação das mulheres.

Essas áreas, assim como a Física, têm resistido a uma análise feminista, por conta do mito da neutralidade, ou que áreas assim são mais impessoais e livres de valores que outras pelos métodos que utilizam ou seus objetos de pesquisa; ou para 'preservar' a objetividade (CABRAL, 2006, p. 41).

Em nome desta "neutralidade científica" das chamadas ciências duras na academia, as estruturas hierárquicas, as regras de gestão universitária, a distribuição de poderes, a cultura organizacional, enfim o habitus do campo acadêmico reflete valores que são reconhecidos socialmente como legítimos e quase nunca são questionados.

\section{Cultura e Campo Acadêmico}

A referência ao trabalho docente universitário foi nomeada nesse tópico a partir das leituras de Bourdieu (2013) que atribui a este espaço as nomenclaturas "campo acadêmico" e “campo de saber" como uma disputa de poder, não só de gênero, mas de forma geral entre todos os que participam deste ambiente.

Neste contexto, a formação cultural e intelectual, segundo Bourdieu (2008), ocorre por meio de incorporação de habitus compreendido como um sistema socialmente constituído de disposições - tendências, aptidões, inclinações, talentos - que orientam pensamentos, 
percepções, expressões, e ações - resultado do longo processo de incorporação coletiva das condições materiais de sua produção (CRUZ, 2012).

A incorporação coletiva citada por Cruz (2012) é o principal ingrediente para a construção do habitus do campo acadêmico. A cultura androcêntrica da sociedade ocidental é absorvida e baseia as relações no campo, "as identidades profissionais são as formas socialmente construídas pelos indivíduos a fim de se reconhecerem uns aos outros no campo do trabalho e emprego" (CRUZ, 2012, p. 32).

A cultura acadêmica condiciona o grau de seriedade da ciência, como adverte Schiebinger (2001), que pode ser traduzido como "dureza da ciência" - no que ela estuda, como ela o estuda, e o grau de dificuldade a ela atribuída - é correlata ao prestígio, aos subsídios e, negativamente, ao número de mulheres no campo" (p. 298). Neste sentido, Hayashi et. al. (2007) dão pistas sobre o baixo número e inferioridade das mulheres no âmbito das áreas exatas e tecnológicas. As/Os autoras/es analisam a produção do conhecimento nos últimos 300 anos e concluem que "a ciência é masculina”. A reprodução no campo acadêmico ocorre porque os grupos tendem a incluir os seus iguais. Em função disso, "muitas mulheres foram, e continuam sendo excluídas da produção da ciência. E mesmo as mulheres dominando numericamente alguns campos disciplinares, a imagem que se faz da figura de cientista, ainda é associada aos homens (HAYASHI et. al., 2007).

\section{Caminho metodológico}

O campo desta investigação envolveu o departamento de Física de uma IFES do nordeste brasileiro, com apenas duas mulheres atuando como docentes, sendo considerado neste estudo como o departamento mais masculino da IFES analisada.

A técnica de coleta de dados empregada foi a de entrevista narrativa biográfica, e foi realizado um ciclo de três entrevistas. Desta forma, buscou-se aprofundar o conhecimento sobre as experiências e vivências da docente. O ciclo de entrevistas é descrito por Kelchtermans (1994) como uma forma de entrevista semiestruturada, organizada de forma cíclica, onde cada entrevista ou etapa é seguida por uma análise que fornece temas para a próxima entrevista ou etapa, de maneira cumulativa, revelando novas peças do que o autor denomina de o "enigma da vida” (p. 95). A realização do ciclo de entrevistas convida a entrevistada a reconstruir suas experiências e trajetória profissional.

A partir das entrevistas foi construída a biografia da docente. Galvão (2005) considera que o uso da narrativa como metodologia de investigação "implica uma negociação de poder e representa de algum modo, uma intrusão pessoal na vida de outra pessoa", uma vez que somos "pelo menos parcialmente, constituídos pelas histórias que contamos aos outros e a nós mesmos acerca das experiências que vamos tendo" (GALVÃO, 2005, p. 330). 
Os dados foram tratados utilizando como ferramenta a análise do discurso. É importante ressaltar que esta técnica de análise não institui uma única maneira de ler um texto, mas uma interpretação que se baseia em argumentos detalhados.

Neste departamento, havia duas professoras no momento da entrevista para a tese de doutorado de uma das autoras, para este artigo, foi escolhida uma dessas professoras que teve uma carreira mais longa. Para manter a identidade da entrevistada em sigilo foi utilizada como código a letra inicial do departamento de Física (F) quando é necessário referência à docente.

\section{A carreira}

As entrevistas com a Professora F ocorreram a em maio e dezembro de 2015 e outubro de 2016, além de alguns dados de uma primeira entrevista realizada em junho de 2010, quando da primeira fase do projeto "guarda-chuva", já mencionado. As entrevistas foram realizadas em sua sala na universidade, em datas e horários previamente agendados.

Logo no início, ao tomar conhecimento sobre o tema da pesquisa, a docente demonstrou conhecimento e interesse pela problemática das relações de gênero na ciência.

Esse problema não é só brasileiro. É internacional e existem instituições preocupadas com isso, que promovem a participação da mulher na pesquisa em Física. Incentivam, criam bolsas específicas para mulheres (...) porque é mundial essa baixa da mulher na carreira de Física.

Indagada sobre as razões dessa reduzida participação de mulheres, apresentou as seguintes considerações:

Olha, quando eu entrei na Física, lá em São Paulo, em 1970, metade do meu curso era de mulheres, metade mesmo: 50\% mulheres, 50\% homens. Eu tinha muitas colegas japonesas (as japonesas iam para as áreas de exatas, como Física, Química, Biologia, Matemática). Eu tinha muitas colegas, realmente a classe era equilibrada, e depois, com o tempo, eu vi que a classe foi esvaziando com relação ao sexo feminino.

É difícil a gente atrair alunos que tenham interesse em fazer Física porque não se sabe, na sociedade de modo geral, para que serve um Físico, acham que Físico é só professor de colégio, não sabem o que é profissão de cientista.

A docente se mostra também curiosa para saber "qual foi o fenômeno que afastou as mulheres dessa carreira”, uma vez que, segundo seu relato, na sua época de estudante, "as mulheres não se sentiam desestimuladas" (F).

\section{O ingresso e desenvolvimento da carreira}

O conceito de gênero é de "difícil compreensão e apropriação até mesmo por pessoas de alto nível de escolaridade, como docentes da educação superior, doutores e doutoras”, como 
dizem Carvalho e Rabay (2015, p. 132), quando não desconhecido, o que, segundo as autoras, “contribui para negar e, consequentemente, perpetuar as desigualdades de gênero" (p.125).

A professora $\mathrm{F}$ tem uma visão mais ampla da situação das mulheres nestes ambientes masculinos e consegue identificar o tipo de situação que a afasta do confronto direto com seus pares masculinos no campo acadêmico.

É uma área muito competitiva e eles brigam entre eles. Eu fico observando, porque, como mulher, a gente não entra nessas brigas. Eu, pelo menos, não tenho vontade de entrar numa briga e de sair mostrando que eu sou melhor que os outros. É um negócio muito machista, é muito acirrada a competição, e como eu também sou uma concorrente, o jeito mais fácil é depreciando, porque eu sou mulher. Então, eles usam todas as armas, para todos os lados. Eu sou vulnerável nesse aspecto [F].

F identifica sua vulnerabilidade no fato de ser mulher e os homens no seu ambiente de trabalho a depreciarem por isso. O que ocorre com as mulheres também em outros ambientes, mas nem sempre elas tomam consciência e identificam as artimanhas masculinas.

Bourdieu (2013) considera o campo universitário como lugar de luta que determina "as condições e os critérios de pertencimento e de hierarquia legítimos, isto é, as propriedades pertinentes, eficientes, próprias a produzir - funcionando como capital - dos benefícios específicos assegurados pelo campo" (p. 32).

A professora $\mathrm{F}$, não tem o mesmo espaço que seus pares para desenvolver suas pesquisas e confessa: "aos olhos do departamento eu não faço pesquisa. Mas, na verdade, eu continuo fazendo pesquisa e continuo atualizada, estudando, trabalhando, lendo $e$ orientando os alunos". Embora a sua aptidão maior fosse para a pesquisa, F acabou se dedicando mais à docência. "De certa forma eu sou forçada, porque já que eu não estou publicando eu tenho que compensar dando aulas e permitindo que outros façam pesquisa".

Essa "permissão" que a professora argumenta, ocorre na forma de facilitação do trabalho dos docentes masculinos, se responsabilizando por ministrar disciplinas menos prestigiadas, auxiliando os alunos orientados por seus colegas nas atividades de pesquisa, ou seja, abrindo espaço para que os detentores do "capital universitário" progridam em suas pesquisas (BOURDIEU, 2013).

A professora $\mathrm{F}$ investiu toda sua força produtiva para o desenvolvimento do departamento e, hoje, indagada sobre o fato de ter chegado ao departamento de Física na década de 1980, já com pós-doutorado, e sobre, do ponto de vista da gestão do departamento, sua capacidade ser "desperdiçada”, porque não participa mais do quadro da pós-graduação, não está inserida em nenhum grupo de pesquisa, ela responde:

Naquela época, eu acho que agi bastante no sentido de melhorar o departamento... Com relação à infraestrutura, condições de pesquisa, a 
motivar as pessoas. Mas, depois chegou a época em que eu quis me dedicar mais à produção científica e aí foi quando eu me senti decepcionada com o jeito como a Física está sendo feita [F].

Eu acho que em grupo realmente é muito mais saudável o estudo, porque se você está sempre isolada, focalizada, você olha sempre em uma só direção, mas se você está discutindo com alguém, a pessoa pode de uma hora para outra, virar toda a perspectiva e você ver: "nossa, porque eu não pensei nisso?" $[\mathrm{F}]$.

Estas falas e a percepção sobre o comportamento adotado por $\mathrm{F}$ denotam a ausência de prática colaborativa e predomínio de práticas competitivas e excludentes entre ela e os docentes masculinos do departamento. Assim como ocorre com F, no jogo de poder e "capital universitário”, como classifica Bourdieu (2013), as mulheres são mais fracas e ou são isoladas ou excluídas. Podemos verificar também, analisando o que ocorre em outros ambientes predominantemente masculinos que a competição entre homens é entre iguais, já entre homens e mulheres é entre desiguais, e as mulheres saem em desvantagem.

Os privilégios masculinos foram criados e alimentados durante toda a existência da humanidade, e, atualmente, por mais que as mulheres já tenham ocupado alguns espaços, as diferenças ainda persistem e as impedem de alcançarem os mesmos patamares dos homens.

\section{Atividades Administrativas}

As diferenças também se reproduzem nas atividades administrativas. O trabalho realizado pelas mulheres, mesmo em ocupações consideradas pelo senso comum como "mais nobres", como no caso das docentes universitárias, é quase sempre desvalorizado em comparação ao trabalho dos homens (BRUSCHINI; LOMBARDI, 2007). Os postos de comando são sempre reivindicados pelos homens e essa autoridade é aceita, inclusive pela maioria das mulheres. Na universidade, as atividades administrativas de maior prestígio nos postos de comando contêm em si o capital simbólico que se configura como posições de poder.

$\mathrm{Na}$ trajetória da professora F relata sobre os postos administrativos:

Eu já fui coordenadora da Biblioteca, quando ela era clandestina, coordenadora do laboratório, quando ainda não existia laboratório, nós saímos do zero... fui coordenadora da pós-graduação [inicialmente ela era uma das poucas pessoas com doutorado e pós-doutorado no departamento]. Aí depois disso eu encerrei: "eu não quero mais, é muito pesado", porque a gente quer ver as coisas acontecerem e para você ver as coisas acontecerem, nessa universidade pelo menos até antes do Governo Lula, era você fazer mesmo, arregaçando as mangas. Aí chega um ponto que já basta! Você pensa: "já dei a minha parte, agora deixa pra outros" [F].

Analisando os pontos destacados no relato da professora F, foi possível perceber que inicialmente, os cargos exercidos foram em espaços ainda sendo implantados, os quais 
precisavam de mais esforço braçal e, geralmente, não davam nenhum prestígio para quem os ocupava, pois os frutos ainda não podiam ser colhidos ou divulgados.

Depois do período de implantação, outros colegas passaram, por exemplo, a coordenar o laboratório, já montado e em plena atividade de pesquisa. Embora ela admitisse "encerrar", não querer mais por ser "muito pesado", foi possível observar durante esta entrevista que o real motivo está na sequência desta fala, quando ela diz querer "ver as coisas acontecerem" e para isso ter que "arregaçar as mangas", denotando ter que fazer sozinha. Ou seja, não pode contar com uma equipe, não tem a colaboração dos seus pares.

A atuação de F como coordenadora da pós-graduação deve levar em consideração que nesta época, ela era uma das poucas pessoas do departamento com doutorado e já tinha dois pós-doutorados, o que somava pontos para o programa de pós-graduação. Entretanto, na medida em que seus pares masculinos defendiam suas teses de doutorado ela ia sendo isolada, até que, chegasse à conclusão que já tinha dado a sua parte de contribuição.

Outro ponto destacado nos relatos da professora $\mathrm{F}$ foi sobre as razões da predominância de homens nos altos cargos da gestão universitária, quando ela diz: "A minha impressão é que as mulheres são bem melhores". Ao insistir no por que, ainda assim, os homens é que ocupam os altos escalões, $\mathrm{F}$ tece o seguinte comentário:

Porque eles acham que são melhores [risos]. Eu não sei, talvez seja porque as pessoas na hora de escolher ainda confiam nos homens, mais do que nas mulheres. São tantos preconceitos que estão na cabeça das pessoas que nem elas mesmas sabem, fazem as coisas meio inconscientes. Então a mulher, normalmente, quando disputa um cargo, sempre vem na mente das pessoas que lugar de mulher é na cozinha $[\mathrm{F}]$.

As questões de confiança e preconceito levantadas pela professora F, como estando "na cabeça das pessoas", estão diretamente ligadas ao poder dos dominantes, e também podem ser analisadas à luz dos conceitos de campo e de habitus de Bourdieu (2013), como um "poder sobre as instâncias de reprodução do corpo universitário” (p. 122). O autor considera que, no campo universitário, o poder está especialmente relacionado às crenças dos indivíduos que nele atuam.

Há sem dúvida poucos universos sociais em que o poder dependa tanto da crença, em que ele seja tão verdadeiro, pois, segundo as palavras de Hobbes, "ter poder é ter seu poder reconhecido". Igualmente, não se pode compreender completamente os fenômenos de concentração do poder universitário sem levar em conta também a contribuição que lhe trazem os pretendentes, por causa das estratégias que trazem para os protetores mais poderosos. Estratégias do habitus, portanto mais inconscientes que conscientes (BOURDIEU, 2013, p. 125-126). 
Como observa Bourdieu (2011, p. 46), "os dominados aplicam categorias construídas do ponto de vista dos dominantes às relações de dominação, fazendo-as assim ser vistas como naturais". Desta forma, legitimam as práticas determinadas pela visão androcêntrica: "pelo fato de suas disposições resultarem da incorporação do preconceito desfavorável contra o feminino, instituído na ordem das coisas, as mulheres não podem senão confirmar seguidamente tal preconceito" (BOURDIEU, 2011, p. 44).

Foi possível constatar que, na visão de F, apesar de as mulheres serem aptas e competentes a assumirem cargos de gestão elas não se dispõem a concorrer com os homens pelos cargos de maior prestígio e poder, assumindo, quando é conveniente também para os homens, os cargos subalternos a eles.

\section{As relações com os pares masculinos e discentes}

As relações entre os homens e as poucas mulheres nos departamentos pesquisados ocorrem de forma parecida com as que se dão em outros espaços na sociedade. Serem semelhantes nas profissões não implica em que as atribuições os/as aproximem, nem impede que a dominação masculina seja exercida, principalmente nestes ambientes majoritariamente masculinos.

A professora F, indagada sobre como acha que é vista pelos colegas, responde que "eles acham que eu sou uma pessoa que eles não precisam temer".

Eu me coloco numa posição um pouco afastada, como que observando o comportamento deles [...] não estou interessada em mostrar que sou melhor do que ninguém [...] eles são todos motivados para mostrar que são melhores, você vai numa reunião de departamento e você vê que eles se manifestam para falar, vem outro e fala a mesma coisa, e eu fico vendo aquele exibicionismo desnecessário. O que eu noto é realmente essa competição entre eles e fico mais como observadora. Eu não tenho nenhum problema... [F].

O comportamento competitivo masculino no departamento é percebido por $\mathrm{F}$ como restrito ao ambiente de trabalho, a visão sobre os colegas fora do departamento, é destacada pela professora como um relacionamento pessoal "ótimo, eu tenho colegas de muitos anos, que estão desde que eu entrei aqui e são meus amigos e a gente conversa normalmente, sem problema nenhum”. Mas é possível analisar que ela opta por se afastar de comportamentos que ela considera desnecessários e exibicionistas, como destacado na fala anterior. Ela não compete com os homens pelo capital universitário que se traduz em posições de poder. $\mathrm{Na}$ forma que F se posiciona há certo cansaço em lutar as batalhas por prestígio e status, tão caros aos acadêmicos.

Sobre a única colega mulher no departamento, $\mathrm{F}$ também não mantém uma relação mais próxima "de fato a gente não se vê, porque ela trabalha lá no laboratório, eu encontro com ela mais no teatro, no Espaço Cultural, do que aqui”. O fato de serem apenas duas mulheres 
em um departamento com 32 homens não as aproxima e elas não colaboram em seus respectivos projetos. Caso elas exercessem atividades mais próximas esta sensação de isolamento possivelmente diminuiria.

As mulheres em departamentos masculinos, apesar das conquistas, ainda têm um longo caminho a percorrer em suas conquistas, pois, mesmo não sendo impedidas de adentrar nestes campos, sua permanência e convivência confortáveis são dificultadas por pequenas e sutis intervenções dos homens que dividem o espaço com elas. Argumentamos que são mensagens sutis de não pertencimento que vão dificultando a integração das mulheres como observaram Zastavker et. al (2011) em seu estudo.

Em relação aos alunos, no departamento de Física, as duas docentes que atuam têm pouca atividade docente no próprio curso de Física, ministram aulas em outros cursos. Apesar disso, foi possível perceber que, no departamento de Física, as pouquíssimas professoras (três em toda a história do curso, sendo na época da coleta de dados uma aposentada e duas em atividade), em geral, não tiveram problemas com os alunos, como também relata a professora F.

Eu procuro investigar, dar disciplinas que não tenham muitos alunos para que eu possa acompanhar o desenvolvimento. Então, eu dou aula no profissional, e evito o básico porque assim eu posso acompanhar mais de perto.

A princípio pode parecer neste relato que F quer evitar o trabalho pesado (escolhendo turmas com menos alunos), mas ao aprofundar este ponto foi possível identificar que sua intenção é investir na qualidade da formação dos discentes, acompanhando-os mais de perto no âmbito profissional.

Foi possível constatar nas narrativas, que a relação com o corpo discente é tranquila, não havendo muita influência no sentimento de pertencimento a este universo masculino em função do tratamento dado e recebido pelos/as alunos/as.

\section{Vida Pessoal e Carreira}

A professora F conta que sua dificuldade com o casamento se deu por seu marido não ser acadêmico. Ele era técnico e ela o conheceu no laboratório onde trabalhava. Ela diz que sempre tomava muito cuidado para não ofender o marido, "porque ele se sentia inferiorizado com a minha progressão de carreira, e isso aí dificultou”. O sucesso profissional dela não encontrava apoio e incentivo no casamento, ao contrário, era preciso abafar seu entusiasmo e motivação para não o ofender o marido.

Para que o marido se sentisse bem, F se auto impunha obrigações domésticas para além das cobranças sociais. Ela narra que sentia "uma carga muito grande de tomar conta da casa e continuar a carreira”. Apesar de se sentir inferiorizado, não era o marido que fazia esta cobrança. 
Não porque ele me pressionasse, mas porque eu mesma achava que tinha que fazer tudo, me obrigando a administrar a casa, a assumir todas as responsabilidades. Eu cedia demais, sempre coloquei à frente as preferências dele. Então, chegou a um ponto em que eu vi que não estava mais vivendo a minha vida. E a gente resolveu acabar, ele não queria acabar, mas eu quis [F]. Eu nunca sonhei ter filhos, esses sonhos não faziam parte de mim, eu não fui criada para isso. Minha mãe criou as três filhas para que elas fizessem sucesso, para que elas conquistassem aquilo que almejavam, e a gente nunca almejou ser mãe. Foi natural pra mim, eu adoro crianças, mas não me vejo como mãe $[\mathrm{F}]$.

F relata que não foi uma decisão fácil, mas priorizou sua carreira, quando diz que não estava mais vivendo a própria vida, está se referindo às atividades acadêmicas que tinham sempre que ser deixadas de lado para que pudesse dar conta de tudo o que se impusera na vida familiar.

\section{Considerações finais}

Foi possível identificar que as relações de gênero interferiram na trajetória profissional da docente biografada, pois apesar de ter sido uma estudante brilhante e ter ingressado na carreira docente concorrendo com os homens por uma vaga, ela não atingiu o ponto alto da carreira acadêmica em termos de prestígio. Ao contrário, a professora $\mathrm{F}$ chegou ao departamento como uma estrela em ascensão - foi até coordenadora do programa de pósgraduação, quando ainda havia poucos doutores no departamento de Física e com o passar do tempo foi se apagando, ou sendo apagada pelas brigas e competições internas.

Ao final da coleta de dados, a professora $\mathrm{F}$ realizava pesquisas para sua satisfação pessoal, mas, no departamento, atuava apenas ministrando aulas para a graduação. Mesmo tendo ingressado na profissão com pós-doutorado, acabou se isolando ou foi deixada à margem por seus pares masculinos no departamento. Atualmente, a professora se aposentou, mas continua trabalhando voluntariamente.

Apesar de perceber a diferença no trato profissional com seus pares, a professora $\mathrm{F}$ atribui apenas às suas decisões pessoais e preferências acadêmicas a sua estagnação na carreira. A docente não percebe que o ambiente hostil a que esteve submetida teve influência no seu comportamento e decisões sobre a ascensão na carreira. O chamado "teto de vidro" esteve o tempo todo presente em sua trajetória acadêmica.

Sugere-se que estudos semelhantes sejam realizados em outras IFES que tenham o mesmo perfil de departamentos e cursos classificados como mais masculinos e que sejam realizadas pesquisas mais amplas, ouvindo os pares masculinos e até mesmo os discentes.

\section{Referências}

BOURDIEU, P.. Homo Academicus. 2. ed. Florianópolis: Ed. da UFSC, 2013.

. A Dominação Masculina. 10.ed. Rio de Janeiro: Bertrand Brasil, 2011. 
BRUSCHINI, C,; LOMBARDI, M. R.; MERCADO, C.; BIZZOCHI, M. (org.) Mulher, Trabalho e Família. In: Banco de Dados Sobre o Trabalho das Mulheres. São Paulo: Fundação Carlos Chagas, 2007. Disponível em: <http://www.fcc.org.br/bdmulheres/serie2.php?area=series $>$. Acesso em: 10 nov.2015.

CABRAL, C. G. O conhecimento dialogicamente situado: histórias de vida, valores humanistas e consciência crítica de professoras do centro tecnológico da UFSC. Tese. 430 p. Florianópolis: Universidade Federal de Santa Catarina, 2006.

CARVALHO, M. E. P.; RABAY, G. Usos e incompreensões do conceito de gênero no discurso educacional no Brasil. In: Revista Estudos Feministas. [online]. 2015, vol. 23, n. 1, pp. 119-136. ISSN 0104-026X. Disponível em: <http://dx.doi.org/10.1590/0104026X2015v23n1p/119>. Acesso em: 08 nov.2016.

. Gênero e Educação Superior: alguns apontamentos para pensar a questão. João Pessoa: Editora da UFPB, 2014.

; SILVA, L. B. Carreiras docentes de mulheres em departamentos masculinos: mudanças geracionais. Seminário Internacional Fazendo Gênero $10^{\mathrm{a}}$ edição - Desafios atuais dos feminismos. Florianópolis, SC: UFSC, 2013.

. Relações de gênero na formação e carreira docente em engenharia mecânica e física no Brasil. In: VIADEL, Antonio Colomer (ed). América Latina, Globalidad e Integración. Madrid: Ediciones del Orto, Ediciones Clásicas, S.A., 2012. v. 3. p. 1467-1474.

CASTElls, M. O Poder da identidade - A era da informação: economia, sociedade e cultura, vol. II. São Paulo: Paz e Terra, 2010.

CHABAUD-RYCHETER, D.; GARDEY, D. Técnicas e gênero. In: HIRATA, H. et al (orgs). Dicionário Crítico do Feminismo. São Paulo: Editora UNESP, 2009, p. 241-245. CRUZ, Maria Helena Santana. Mapeando diferenças de gênero no ensino superior da Universidade Federal de Sergipe. São Cristóvão: Editora UFS, 2012.

GALVÃO, Cecília. Narrativas em educação. In: Ciência \& Educação, Bauru, SP, v. 11, n. 2, p. 327-345, 2005.

HAYASHI, Maria C. P. I; CABRERO, Rodrigo C.; COSTA, Maria P. R.; HAYASHI, Carlos R. M.Indicadores da participação feminina em Ciência e Tecnologia. In: TransInformação, Campinas, maio/ago, 2007, p. 169-187.

KELCHTERMANS, Geert. Biographical methods in the study of teachers' professional development. In: CARLGREN, Ingrid; HANDAAL, Gunnar; VAAGE, Sveinung (Eds). Teachers' minds and actions. The Falmer Press. 1994. Disponível em: <https://www.researchgate.net/publication/263227928>. Acesso em: 08 nov.2016. 
KERGOAT, Danièle. Divisão Sexual do trabalho e relações sociais de sexo. In: HIRATA, Helena et al (orgs). Dicionário Crítico do Feminismo. São Paulo: Editora UNESP, 2009, p. 67-75.

PÉREZ SEDEÑO, Eulalia. A modo de introducción: las mujeres en el sistema de ciencia y tecnologia. In: PÉRES SEDEÑO, Eulalia (Ed.). Las mujeres en el sistema de ciencia y tecnología - estudios de casos. Madri: OEI, 2001.

SCHIEBINGER, Londa. O feminismo mudou a ciência? Bauru, SP: EDUSC, 2001.

STEIL, Andrea Valéria. Organizações, gênero e posição hierárquica: compreendendo o fenômeno do teto de vidro. Revista de Administração da Universidade de São Paulo. RAUSP, v.32, n.3, p.62-69, julho/setembro 1997.

ZASTAVKER, Yevgeniya V.; GUEYE, Paul; MACK, Kelly M.; IVIE, Rachel; SIMMONS, Elizabeth H.; SANTOS, Lea F.; MARTÍNEZ-Miranda J.; BIENENSTOCK, Arthur; BLICKENSTAFF, Jacob Clark; RENEE HORTON, Kimberly; MACLACHLAN, Anne J.; BERRAH, Nora e HARTLINE. Beverly K. Women in Physics in the United States. In: AIP Conference Proceedings. 2009. Disponível em $<$ http://scitation.aip.org/content/aip/ proceeding/aipcp/1119?ver=pdfcov>. Acesso em: 05 jul.2015.

\section{Biografia Resumida}

Lucimeiry Batista da Silva, Graduada em Administração, Mestra em Administração e Doutora em Educação, tanto a graduação quanto as pós-graduações foram realizadas na Universidade Federal da Paraíba, Campus I - João Pessoa. Professora do Departamento de Administração, do Centro de Ciências Sociais Aplicadas (CCSA), da Universidade Federal da Paraíba (UFPB) Campus I - João Pessoa-PB. Integrante do Núcleo de Estudos em Aprendizagem e Competências - NAC/UFPB.

Lattes: http://lattes.cnpq.br/9414391935846439.

Contato: meiry11@gmail.com

Glória de Lourdes Freire Rabay, Graduada em Jornalismo, pela Universidade Federal da Paraíba (UFPB), Mestra em Sociologia pela Universidade Federal da Paraíba (UFPB) Campus I - João Pessoa e Doutora em Sociologia pela Universidade Federal do Rio Grande do Norte (UFRN) em Natal. Professora do ISSN 2526-2882

$$
\text { * 387 }
$$


Departamento de Jornalismo, Centro de Comunicação, Turismo e Artes e professora dos cursos de Pós-Graduação em Jornalismo, também no CCTA e do Mestrado em Direitos Humanos do Centro de Ciências Jurídicas (CCJ) da Universidade Federal da Paraíba (CCTA/UFPB) Campus I - João Pessoa-PB. Pesquisadora do Núcleo Interdisciplinar de Pesquisa e Ação Sobre Mulher e as Relações de Sexo e Gênero da UFPB (NIPAM/UPBB).

Lattes: http://lattes.cnpq.br/0479694352894279.

Contato: gloria.rabay@gmail.com 